\title{
Beyond the Eclipse of Reason: On the Reconstruction of Rationality
}

\author{
Graziano Lingua
}

What task has the passage into the new millennium bequeathed to a European philosophy that intends to understand its own time in thought and that does not wish to remain indifferent to social and political dynamics? Without attributing excessive significance to a date that simply marks the progression of the calendar and not an epochal change, it is still true that, the further we get from that date, the clearer it becomes which aspects of last century's sensibility no longer belong to us and what, instead, may still be a living and fertile inheritance.

To begin with, it becomes clearer which cultural dynamics characterised the thought of an age marked by the effort to distance itself from the project of modern reason, in order to comprehend not only its potential, but also its fatal limits and errors. The main events that characterise the first half of the $20^{\text {th }}$ century, with its two World Wars and the experience of totalitarianism, put the crisis of the modern project firmly on the horizon, a crisis already under way by the end of the $19^{\text {th }}$ century, with Marx's analysis of capitalist production and the Nietzschean discovery of the nexus between reason and the relationships of domination between the subject and society. The material and spiritual tendencies of this crisis can be filed under many labels: the 'disenchantment of the world' (Max Weber), the 'uneasiness of civilisation' (Sigmund Freud), the 'decline of the West' (Oswald Spengler), the 'crisis of European humanity' (Edmund Husserl), all expressions that seek to give voice to discontent in their appeal to a cultural and social model that has proven unable to keep its ambitious promises.

At the forefront of the inexorable hiatus between the hope for social justice, autonomy and individual freedom, and the reality of a society in which the effects of rationality dominate to a perverse degree, a destructive pathos begins to emerge, as if the only option left for thought is to depart, leaving behind something not only inadequate, but also dangerously violent and illusory. After Auschwitz, Hiroshima and Stalinism's mass exterminations, what is shattered are not just the grand narratives 
of the philosophical and religious tradition, but even the very foundational framework of rights as instruments through which justice can prevail. On the one hand, these events seem to confirm diagnoses of the end of metaphysics and the victory of nihilism; on the other hand, they substantiate analyses of the triumph of technique, instrumental thought and the reification of consciousness, anticipated by Max Weber and Martin Heidegger and significantly re-explored in The Dialectic of Enlightenment by Max Horkheimer and Theodor W. Adorno, a book that non-coincidentally was published in 1947, a time in which the concrete effects of the crisis of modern reason had been felt at full strength.

At that time, speaking about the dialectic of enlightenment entailed the impossibility of separating the ideal plan of the Aufklärung from the ways in which it took shape in events which the West both crafted and suffered; and therefore also entailed that modern reason already possessed, in nuce, a grasp of the origins of its own crisis and its reversal into the realm of violence. Nevertheless, it must be recalled that The Dialectic of Enlightenment was born of a philosophical gesture already motivated by an emancipatory hope, subsequently diminished through the radicalisation of criticism and the consciousness of the irreversibility of its failure. It would be through the subsequent events of the Second World War that suspicion and demystification produced an increasing mistrust of every attempt at an adequate philosophical response, but also a deepened scepticism towards the very possibility that reason could render itself a governmental instrument for controlling social complexity and a motivator for individual and collective action. From this point of view, the postwar period seems to confirm the most negative analyses offered in the first half of the century by Weber and Heidegger. The increasingly marked extension of instrumental and technological rationality would accentuate scepticism concerning the possibility that a mode of thought might arise that was capable of meeting both the individual's and society's demands for meaning, as well as reining in the systemic dominion of the 'reign of technique'. To all this can be added the polytheistic outbreak of increasingly multicultural values and connotations, typical of the society of the last decades of the $20^{\text {th }}$ century. This exposes philosophy to a constant oscillation between, on the one hand, capitulation to relativism and irrationalist impulses, and on the other hand simplistic attempts to return to models prior to the crisis.

1 Cf. Ferry 1996, 85. 
It is not difficult, however, to perceive in the 1970s the moment in which the destructive dimension of the critique of modern reason became sharpened and in which the inheritance of a philosopher such as Heidegger was put to use in its capacity for a more radical unmasking of the pretensions of the modern plan. From this point of view, the philosophies of Jacques Derrida and Richard Rorty are emblematic, along with the French post-structuralist thought of authors such as Michel Foucault and Gilles Deleuze. In this context the prolongation of Heideggerian hermeneutics becomes radicalised in a demystificatory gesture: not the slightest residue of sense escapes the corrosive critique of language bequeathed by these thinkers and not a single argumentative gambit can sustain the search for a truth that goes beyond a poetic/metaphorical declaration. As Gianni Vattimo remarked about Derrida, philosophy becomes free of every founding gesture, but to do so it increasingly resembles a performance, the effect of which is not easily distinguished from that of an aesthetic experience'. ${ }^{2}$

From this point of view, the - in the general sense - 'deconstructive' sensibility can be seen as the extreme effect of a distancing of the modern project and thus effectively becomes one of the terms on which the legitimacy of the radical critique of reason is assessed. Yet is there truly nothing left over once reason has undergone this process of radical dissemination? Must we accept that it has been deformed by an intrinsically deceptive and violent totalitarian dimension, and must therefore be considered a repressive tool, to be distrusted? If one examines what has occurred in philosophical debate over the last two decades of the $20^{\text {th }}$ century, it would seem that the answer is 'no'. Rather, the last stage of transition from the 1900s bequeaths to the new millennium an evident inclination to move away from a purely destructive criticism and underlines an attitude that we could define as 'reconstructive', that is, characterised by a positive need 'to reconstruct' rationality on a new basis, recognising the legitimacy of appeals to truth on behalf of philosophical discourse, such as might justify a rational critique of language and thought. This counter-tendency to the kind of radical demystification involved in the idea of a total eclipse of reason is registered in all those forms of thought that do not give up all claims to truth and which seek out the positive conditions of a non-metaphysical deployment of modern reason extending to its ethical and social aspects. The signs of this are also often found outside the realm of strictly academic reflection. They underline a precise

2 Vattimo 1997, 101. 
demand for standards of validity in public discourse and social action that cannot be limited to the aesthetic and paradoxical postures to which deconstruction has accustomed us. It is, moreover, against the 'impolitic' effects of these postures that risk legitimising diffuse forms of cynicism and irresponsibility, ${ }^{3}$ that the need for a new positive-critical responsibility for thought has become more evident.

However, there is need to reach agreement on the meaning of this reconstructive attitude and on the use of the term 'reconstruction' because it can, as with 'deconstruction', become simply an empty slogan, devoid of genuine meaning. Thus, rather than a precise philosophical category, by reconstruction I mean here a widely shared sensibility that can be perceived on many levels and be spoken in many ways. Recognising this indeterminacy, which makes it difficult to offer a precise map of authors and a consolidated topography of subject-areas, in the following pages I will begin by proposing a hypothesis for reading this sensibility, by covering the thought of three exponents of continental philosophy, Jürgen Habermas, Paul Ricoeur and Jean-Marc Ferry, seeking to thematise, from each point of view, the reconfiguration of rationality. I will use some of their fundamental intuitions as a terrain of philosophical experimentation for the concept of reconstruction, without pretending to offer an exhaustive historiography. My goal, rather, is to show that the reconfiguration of rationality cannot consist in a regressive attitude to the crisis of reason, in a simple 'return to the past', avoiding exposure to more radical forms of deconstruction, but must instead pursue to the end the demystifying dimension intrinsic to the philosophies of crisis, without limiting itself to their deconstructive side. Through these three thinkers, I will try to demonstrate that the philosophical use of the notion of reconstruction, and specifically the reconstruction of rationality, is legitimate only if it succeeds in bringing to light reconstructive resources present within the demystificatory critique; resources that become essential to answering - to paraphrase Ricoeur's famous formula - the question whether modern reason's project is still capable of 'giving rise to thought'.

3 Cf. Putnam 1992, 132-133; Ferraris 2010. 


\section{The communicative reconstruction of rationality: Jürgen Habermas}

Habermas is undoubtedly one of those European authors who best express this spirit of a rehabilitation of reason, against the diagnosis of the death of rationality. His position is in favour of a reconstruction of the modern plan of rationality, against the various formulations that are programmatically defined as 'postmodern', yet it is not opposed to the idea of a crisis of reason. Indeed, his belonging to the Frankfurt School means that Habermas is deeply conscious of the problem posed by Horkheimer and Adorno in The Dialectic of Enlightenment. In Habermas's philosophy one finds an alternative research route to those of the philosophies that limit themselves to denouncing the crisis of Western rationalism, the triumph of the instrumental spirit and the distortions of public communication. As one can read in an essay of 1970, according to Habermas, every critique demystifying communication must presuppose that there exists, at least ideally, a form of communication that has not been degraded, ${ }^{4}$ that can therefore make use of a non-mystificatory critique. For the analysis of the deformed structures of communication to be possible, it is therefore necessary to presuppose a form of intact communication which can be offered as an ethical ideal of humanity, the ideal of a community of communication free from any kind of domination. It is therefore not true that all rationality is totalitarian, or that its instrumental use is the only possibility, since an alternative exists which Habermas, following Apel, identifies with a discursive-procedural model of rationality whose objective is the cooperative construction of understanding via argumentative discussion.

From the outset, one can see that the goal of this discursive model of rationality consists in reconstructing the conditions that render successful communication possible, and thus offer an exercise of reason that does not have to be illusory or the product of false consciousness. Habermas does not simply aim to revive reason from outside through a sense of commitment to its validity, and nor does he propose a metaphysical substantialism, or simply re-assume a philosophy of the subject. Rather, he deems it necessary to recognise and make explicit that which is implicit in every critical act of speech that seeks validity and that in order to legitimate its own validity, passes through an intersubjective procedure of

4 Habermas 1970, 360-375. On this aspect, see Cunico 2009, 24. 
validation. He who sets up to take part in this discussion must already presuppose a series of conditions that render it possible: a practical discourse is inconceivable without postulating that the protagonists themselves adhere to the norms they have recognised if they expect their speech to be valid. This evidently entails a strong dose of idealisation: such a communicative reason founds its validity on a series of postulates (openness of access, equal freedom of speech, absence of external constrictions, sincerity of interlocutors, etc.) which are inevitably counter-factual because they do not occur in ordinary communication, in which distortions of various kinds operate. ${ }^{5}$

Now, the utopianism of this ideal speech situation is one of the elements most strongly condemned by critics, ${ }^{6}$ since the Habermasian reconstruction would seem ultimately to presuppose an unreal form of communication, devoid of effect in social practice. Habermas is aware that the existing concrete form of the argument does not satisfy these presupposed conditions, and on this basis recognises the counter-factuality of the argument; however he judges it necessary in order to render the confrontation possible and in order to create the conditions for understanding. Actually, as Ferry makes clear, ${ }^{7}$ the validity of these idealisations cannot be refuted on the basis of existing empirical limits to communication, because its function is regulative and indicates the intrinsic normativity of communicative action. This intrinsic normative quality emerges clearly from the 1980s onwards when Habermas, starting from the theory of communicative rationality, starts to elaborate his discourse ethics (Diskursethik). ${ }^{8}$ In this case, too, the reconstructive instance coincides with the necessity to recognise specific normative ties ${ }^{9}$ that must be presupposed on the part of every social actor who intends to reason, and who cannot deny them without falling into a pragmatic self-contradiction.

5 Cf. for example Habermas 1979, 1-68. On this aspect of Habermas's thought, see Lafont 1999, $141 \mathrm{f}$.

6 For a picture of the critiques against the Habermasian position, see Benhabib 1995, 330-339.

7 Ferry 2010, 148.

8 See Habermas 1990a; Habermas 1993.

9 These normative ties are declined in the principle of universalisation (U) - according to which moral norms must have the form of universal unconditional propositions founded upon universal interests - and in the principle of discussion (D) - that requires a basis of validity to every norm acting on a consensus obtained through argumentation. Cf. Habermas 1990a, $120 \mathrm{f}$. For an analysis of these principles, see Ingram 2010, 131-138. 
To me it seems that the most productive kind of criticism is that which focuses on the Habermasian thesis that argumentation is the only register of discursive validity. ${ }^{10}$ Regarding both epistemology and moral issues, Habermas opts for a procedure in which the only resource of intersubjective validation is the rational force of argument. In the argumentation a non-coercive cogency of the better argument must prevail, that is, the argument that best succeeds in generating consent from others. ${ }^{11}$ This option becomes particularly problematic from the practical point of view, when it is not just issues of fact that are involved, but also values and convictions less easily translatable into argumentative terms which nevertheless strongly condition the positions taken by various protagonists in a discussion. To focus, as with Diskursethik, the cooperative construction of norms on the single register of argumentation risks producing a restrictive effect on discussion. This is because it excludes, from the formation of understanding, the social actors, who are inadequate at the level of rational-discursive logic, but all the same able, as Giacomo Marramao says, 'to give an account of their own chosen ethics or the consequences the autonomous or heteronomous adoption of determined norms and styles of life involve in their existence'. ${ }^{12}$

A tension is generated therefore that risks compromising from within the inclusivity of communicative reason. On the one hand, it means remaining receptive to every form of speech on the condition that the normative presuppositions for acting and for understanding are recognised. But, on the other hand, the restriction of the criteria of validity to the argumentative register alone has the effect of making it difficult to integrate deeper motives into the discussion, such as individual biographies and contexts of belonging, that can often only be expressed by informal registers, as happens for example in moral doctrines of a religious character. The attempt by Habermas in his most recent work to open communicative reason to the contributions of religion demonstrates this internal tension in his thought. ${ }^{13}$ On the one hand, Habermas recognises the necessity to transcend positions like that of Rawlsian liberalism that imply an exclusion of religious doctrines from the public debate in which the political will is formed. Yet on the other hand, he demands that the some-

10 See for example Ferry 1996, 86-104.

11 Habermas 1984, 25.

12 Marramao 2008, 82.

13 On the role of religion in the late Habermas, see Cunico 2010; Lafont 2007, $239-259$. 
how 'mythical-symbolic' content of religions be translated into a secular language accessible to all. The 'institutional translation proviso ${ }^{14}$ required by Habermas, then, involves a process of rationalisation which demythologises these contents, that is, a secularising transposition of the particular convictions into a universal reason. Now, this transposition is not without its own problems, since either one immediately acknowledges that citizens who are also religious believers are able to express their convictions in a language that is accessible to everybody (and therefore recognises a form of rationality even within the symbolic resources of the religions concerned) or it becomes unclear how - thanks to the cooperative contribution of secularised citizens - a private conviction might become universalisable where previously it was not. ${ }^{15}$

\section{Beyond demystification: Paul Ricoeur}

The tension present in late Habermas shows how his proposal - though it has unquestionably constituted a barrier against the deconstructionist vogue - contains at its core a residue of rationalism. It is a form of rationalism which has the appearance of an excessive optimism towards the emancipatory force of communication, and which ends by espousing a much less inclusive rationality than what Habermas himself would have liked. This limitation becomes still more obvious if a series of thematic constellations that in the last two decades has acquired importance in philosophical debate is considered. It seems to recall the demand for a reason principally attentive to concrete contexts and the 'extra-argumentative' elements that contribute to constructing real identities and motivate the life of social actors. One might think, for example, of the ambiguous phenomenon of the 'return of the religious ${ }^{16}$ that seems to put in doubt the irreversibility of the process of secularisation and alludes to a renewed need for symbolic resources, or the growing attention to the individual and collective convictions which refer more to intuitive values than to reasoned arguments. ${ }^{17}$ Or again, the re-emergence of the problem

14 Habermas 2006b, 10.

15 On this topic, I permit myself to refer the reader to Lingua 2010, 20-27.

16 For a sociological analysis of the phenomenon, cf. Casanova 1994; Norris/Inglehart 2004. For an interesting synthesis of these philosophical aspects, see Tosel 2011. While on the contemporary aspects of secularisation one must not overlook Taylor 2007.

17 For instance, cf. Joas 2000. 
of myth, interpreted not only as content to be rationalised but as an authentic form for the transmission of meaning at the social level and as a source of normativity. ${ }^{18}$ These themes, then, find their centre of gravity in the philosophical interest in narrative as a discursive register more closely bound up with the history of existence and less with abstract argumentation. ${ }^{19}$

Paul Ricoeur is without doubt one of those contemporary authors who best display a sensibility towards the recovery of the philosophical dignity of these expressive and identificatory dimensions, as well as an attention to the veritative and normative force of history. His hermeneutics represents a particularly interesting contribution that helps to clarify what I have termed 'the reconstructive sensibility', because the valorisation of the symbolic order that it proposes assumes from its outset the demystifying critique, yet without being limited to that negative dimension. In his works from the 1960s, Ricoeur approaches interpretation as an exercise of unmasking those he termed, in a felicitous phrase, the 'masters of suspicion', by applying a different hermeneutics, founded on the 'recollection of meaning, ${ }^{20}$ that is, on a movement towards a reconstitution of meaning. This dualism returns in the form of various binaries that always recalls the need to avoid reducing the relationship with symbolic material to a simple negative genealogy: think, for instance, of the difference between 'reductive hermeneutics' and 'restorative hermeneutics', or of the difference between 'demythization' and 'demythologization'. ${ }^{21}$ The idea of restoration and of demythologisation recall the fact that, 'it is beyond destruction that the question is posed as to what thought, reason and even faith still signify. ${ }^{22}$

However, going beyond destruction does not mean choosing one of the two poles of the binary and cancelling out the other. Rather it means seeking to keep them in constant dialectical relation. The philosophies of suspicion do an important job on symbolic material because mythos, or narrative, has always been a means of masking or dissimulating origins, a technique by which language says indirectly what cannot be

18 For instance, cf. Legendre 1999.

19 Think, for instance, of the role played by narration, not only in Ricoeur's thought, but also as analysed by authors such as Charles Taylor (1989) and Alasdair MacIntyre (1984). For an introduction to the meaning of the rebirth of interest in narrative, see Rankin 2002, 1-12.

20 See Ricoeur 1970, 28-32.

21 See Ricoeur 1970, 530; Ricoeur 1989, 185, 326-330, $332 \mathrm{f}$.

22 Ricoeur 1970, 43. 
said directly. Yet these approaches do not take the subsequent steps of rearticulating and re-semanticising the demystified contents. ${ }^{23}$ It is this second aspect that defines the innovation of the Ricoeurian gesture, and that can inspire what Hans Joas called 'affirmative genealogy, ${ }^{24}$ thanks to which the archaeological search into symbolic elements does not result merely in an unmasking of the illusions and a consequent disenchantment or demystification, but the possibility of opening itself to the various levels of meaning that are archived in the language of symbolic-narrative.

The same reconstructive dynamics is also found in Ricoeur's later thought, when starting with Oneself as Another he explores the effect that the recovery of the narrated layers of existence has on ethico-political aspects. For Ricoeur during this period, narration is more directly articulated towards the topic of action and the issue of its moral justification. Once a story enters into the exchange of experiences and intersubjective communication, it is no longer free from being approved or being disapproved, since it is imputable to a person who acts. Linking stories to subject-agents means that mythos does not enjoy an ethical neutrality. ${ }^{25}$ Every narration tells of an action and an actor that make choices that are exposed to appraisal and which therefore trigger a process of blame or justification. This is why in Oneself as Another narration acts as the hinge between the moment of description, as a discourse concerning the factuality of events, and the moment of prescription, that is, the attribution to a lived personage of this event and the responsibility it entails. ${ }^{26}$ Ricoeur thus arrives indirectly at a recovery of the subject, without evading the critique and the suspicion that had transformed it into a 'shattered cogito' and without simply restoring a philosophy of the 'exalted subject'. ${ }^{27}$ Rather this approach institutes a register of multiple and many-levelled sense, the matrix for which resides in the ability of narrative identity to be at the same time a construction of the continuity of vital ties and the place where their validity is judged. It is at this level that the Ricoeurian anthropological reflection becomes explicitly political and that the reconstructive requirement as affirmative genealogy meets the intersubjective

23 I am indebted to the work of Alberto Martinengo for these observations on the reconstructive dimension of dialectic between Ricoeur's hermeneutics, cf. Martinengo 2008b, 43-50.

24 Joas 2009, 15-24.

25 Cf. Ricoeur 1992, 115.

26 Ricoeur 1992, $152 \mathrm{f}$; on these aspects, see Ferry 1994, $60 \mathrm{f}$.

27 Ricoeur 1992, $11 \mathrm{f}$. 
place of justification and validation. Emblematic of this is another conceptual coupling which lends its title to the volume of interviews Critique and Conviction and that resurfaces in other works in the polarity between reasoning and conviction. ${ }^{28}$ Instead of identifying argumentation alone as the instrument of normative justification as Habermas does, Ricoeur proposes to enact a subtle dialectic between argumentation and conviction, according to which only their co-implication or inter-involvement can permit them to make a responsive moral judgment upon concrete situations. And this 'precisely because argumentation is not simply posited as the antagonist of tradition and convention, but as the critical agency operating at the heart of conviction, argumentation assuming the task not of eliminating, but of carrying them to the level of "considered convictions"'. ${ }^{29}$

The valorisation of the symbolic as a form not external but internal to rationality now becomes - due to the ethico-political turn of Ricoeurian thought that occurred in the 1990s - the rehabilitation of contexts in which identity and conviction mature. With respect to these contexts the argumentation is, however, above all an 'abstract segment ${ }^{30}$ of a discursive plural proceeding through which various linguistic games acquire value, games which contribute to forming the positions from which the same arguments themselves acquire value. It is here, then, that the restorative hermeneutics is enriched with new significance: it is no longer only an affirmative genealogy that contrasts with the 'negative' orientation of the masters of suspicion, but rather becomes a wider articulation between genealogy and justification, between narration and discursive validation, in which a subtle dialectic works between the narrative genesis of individual and collective identities and their critical justification.

3. Validity of the argument and vulnerability of the person: The 'reconstructive principle' according to Jean-Marc Ferry

As befits his case for the necessity of re-articulating narration and reasoning, and thereby recovering the validity of the discursive register expressed, Ricoeur's reflection finds an unexpected consonance with some

28 Ricoeur 1991, $161 \mathrm{f}$.

29 Ricoeur 1992, 288.

30 Ricoeur 1992, 287. 
followers of the Habermasian program. ${ }^{31}$ Among these it is worth taking a look at the third figure who interests us here. I refer to the philosophical project of Jean-Marc Ferry, since it makes of 'reconstruction' a programmatic notion whose objective is to value the complementary relation between the historical-contextual resources of narrative and the universalising requirement of argumentation, as fundamental elements of rationality. Its 'reconstructive ethics', ${ }^{32}$ while maintaining the procedural system of Diskursethik, points towards a specific acknowledgment of the individual persons involved, with their particular history that, though often difficult to translate precisely into terms of rational argumentation, nevertheless conditions and structures the concrete positions taken in an argument. The philosophy of Ferry therefore links up with the critical angle of the Frankfurt tradition, with attention paid to the contextual aspects, the role of convictions and the symbolic horizons of hermeneutic enquiry. This lends to 'reconstruction' a strong theoretical capacity, as a notion that not only describes contemporary sensibility, but can also constitute the blueprint of a plan to redefine and to extend public reason.

Against the idea that argumentation constitutes the only modality of discursive validation, Ferry proposes in Les puissances de l'expérience a systematic plurality of forms of speech based on four registers - narration, interpretation, argumentation and reconstruction - each with a specific level of reflexivity and a distinct normative capacity. ${ }^{33}$ With these classifications Ferry does not aim to distinguish diverse genres or formal styles: the discrimination that organises the partition into four categories is in fact pragmatic. It is rooted in the various types of discursive action that are put into play and is able to evidence the variety of elements that is working behind and within the communicative construction of identities. This same conception of a plural system of discursive registers means that none of them can claim exclusive priority, or supremacy as the locus of validity. Rather they all contribute in various ways to communicative rationality. This is valid not only for the register of argumentation - which, as we have seen, represents for Habermas the prime register for the justification through which interlocutors might be persuaded to reach consensus - but also for the narrative dimension to which Ricoeurian hermeneutics, and with it many contemporary speech-act theories, attribute su-

31 I am thinking of several authors such as Seyla Benhabib, Jean-Marc Ferry and Albrecht Wellmer. Cf. Benhabib 1986, 338-339; Ferry 1996; Wellmer 1991.

32 Cf. Ferry 1996.

33 Cf. Ferry 1991a, 103-157. 
premacy in the construction of identity and a 'near-monopoly of the substantial issues. ${ }^{34}$ Ferry thinks that Ricoeur overrates the capacity of the narrative dimension and does not recognise that narration as a discursive register suffers from a logical and normative deficit. ${ }^{35}$ The moment of reconstruction, as the fourth moment of the system, has but one strategic function: being a register of speech in and of itself, it also represents a moment to resume reflection and an opportunity for integration of the previous registers, without being sutured exclusively to any of those particular registers. It allows for a 'shift in the focus of the narrative by structuring them through reasoning, ${ }^{36}$ serving to correct the superimposition that occurs on the narrative level between res factae and res fictae, therefore being able to contextualise not only the sense of a story, but also its claims to truth. If it does not come to maturity reflectively through a critical thematisation of the narrative element of identity, it lends itself rather to processes of ideological auto-justification; thus it is necessary that it decentres itself in more reflective and critical forms that check the tendency towards an idiosyncratic closure. ${ }^{37}$

But why does Ferry call 'reconstruction' the fourth register? Certainly the term refers to a retrospective movement of reflective mediation different from the gesture of deconstruction, even if in Ferry's work there is no direct comparison with deconstruction. The notion of reconstruction, however, should not be read in direct opposition to deconstruction, but rather in relation to the need to break with the formal restrictions and delimitations that are abstract and hardly sensitive to the historical nature of reasoning. Thus, it is necessary to emphasise that reconstruction is not simply reactive and it does not allude to a return to irretrievably lost identities, as if resorting to some tradition that could prevail as such, but works on concrete forms in which are manifested the requirements of a universality of reason. A twofold movement of rationality operates that on the one hand is critico-demystifying in its encounters with every form of dogmatic hypostatisation, comprising the violent forms of argumentative reason, and on the other hand is reconstructive-restitutive, as by recovering the more expressive forms of speech it thematises the need for justification. ${ }^{38}$ It therefore does not propose taking a retrograde

34 Ferry 1991b, 103.

35 Cf. Ferry 1994, 59-70.

36 Ferry 1996, 55-56.

37 Ferry 1996, 43-45.

38 Ferry 1991b, 138. 
step regarding modern critical thought, but rather a step forward, implementing and expanding rationality, so as to render it sensitive to a series of elements that modernity has neglected.

This reconstructed dimension becomes evident in the ethico-political reflection that Ferry declines to depart from in his theory of discursive registers. ${ }^{39}$ In 'reconstructive ethics' a central role is given to the experience of the other and the suffering that may concretely impede intersubjective communication, for which purpose the discussion goes beyond the strictly argumentative style at the basis of rationality to recognise the need for a reconciliation of memory and the recognition of the person. On the ethical side, reconstruction therefore demands a deepening of the requirement for a justification that is not limited to rational validity but is in a position to integrate an acknowledgment of the vulnerability of the subjects involved and of the particular history of which they are bearers. Reconstructive ethics at the same time thus becomes an ethics of recognition of the other's vulnerability, and an ethics of responsibility in the interests of justice and truth cooperatively sought out, without any one of the interlocutors being in prior possession of the key that leads to consensus.

One of the more significant aspects that reconstructive sensibility acquires in Ferry, is its ability to articulate the genesis and justification of validity. From this point of view, reconstruction does not mean merely re-tracing and ordering the historical elements that contribute to identifying the values and the convictions sustained by all, but also implies a critical reconstruction of the origins of these values, helping to overcome the different kinds of violence that may have generated a lack of acknowledgment of the persons involved. The genealogical moment must make reference to criteria of validity, but such criteria cannot be founded on decontextualised a priori claims; they must emerge reflectively in the same experience of communication. For this to happen, 'critical charity ${ }^{40}$ is necessary, that is, an attitude of real openness in comparing the symbolic forms in which beliefs belonging to other sensibilities or cultures are expressed; this openness is the only attitude that can encourage the emergence of that spontaneous ethical attitude of mutual acknowledgment.

39 Cf. Ferry 1996; Ferry 2000; Ferry 2010.

40 Ferry 2004, 204. 


\section{Conclusion}

As one can see from the course I have followed, from Habermas's rehabilitation of reason, passing through Ricoeur's hermeneutics, to the articulation between genesis and validity which leads to Ferry's systematising of public discourses, a philosophical analysis of reconstruction demands the recognition of the plurality of this notion. All the more so when the issue at hand is that of the contemporary reconstruction of reason. There is, however, a common element worth remembering in conclusion, and related to what has already been said about the necessity of thinking of reconstructive sensibility not only in regressive terms, as a simple strategy of 'turning backwards'. It can be summarised as the necessity of not interpreting the expression 'reconstruction of rationality' by giving the genitive a purely objective meaning. The issue at stake in the authors I have examined as a terrain of philosophical experimentation is not rehabilitating reason from outside, for in this case every reconstruction would become a simple 'restoration'. The true challenge is instead the subjectivegenitive sense of that expression: it is the same rationality that from within is called upon to reconstruct itself, that is, to rearticulate itself by taking the process to its logical conclusion in accordance with the destructive critique while recognising, however, that destruction is not the only form of contemporary philosophy that can undertake the task at hand.

Translated by Mike Watson 
Brought to you by | Biblioteca "Erik Peterson"

Authenticated | graziano.lingua@gmail.com author's copy

Download Date | 11/4/12 8:27 PM 